\title{
Dielectrophoretic Microfluidic Chip Enables Single-Cell Measurements for Multidrug Resistance in Heterogeneous Acute Myeloid Leukemia Patient Samples
}

\author{
Avid Khamenehfar, ${ }^{1}$ Maher K. Gandhi, ${ }^{3}$ Yuchun Chen, ${ }^{1}$ Donna E. Hogge, ${ }^{4}$ Paul C. H. Li ${ }^{1,2^{\star}}$ \\ ${ }^{1}$ Department of Chemistry, ${ }^{2}$ Department of Molecular Biology and Biochemistry, Simon Fraser University, 8888 University Drive, \\ Burnaby, BC, Canada \\ ${ }^{3}$ The University of Queensland, Diamantina Institute, 37 Kent St., Woolloongabba, Queensland, Australia \\ ${ }^{4}$ Terry Fox Laboratory, BC Cancer Agency, 675 West $10^{\text {th }}$ Ave., Vancouver, BC, Canada
}
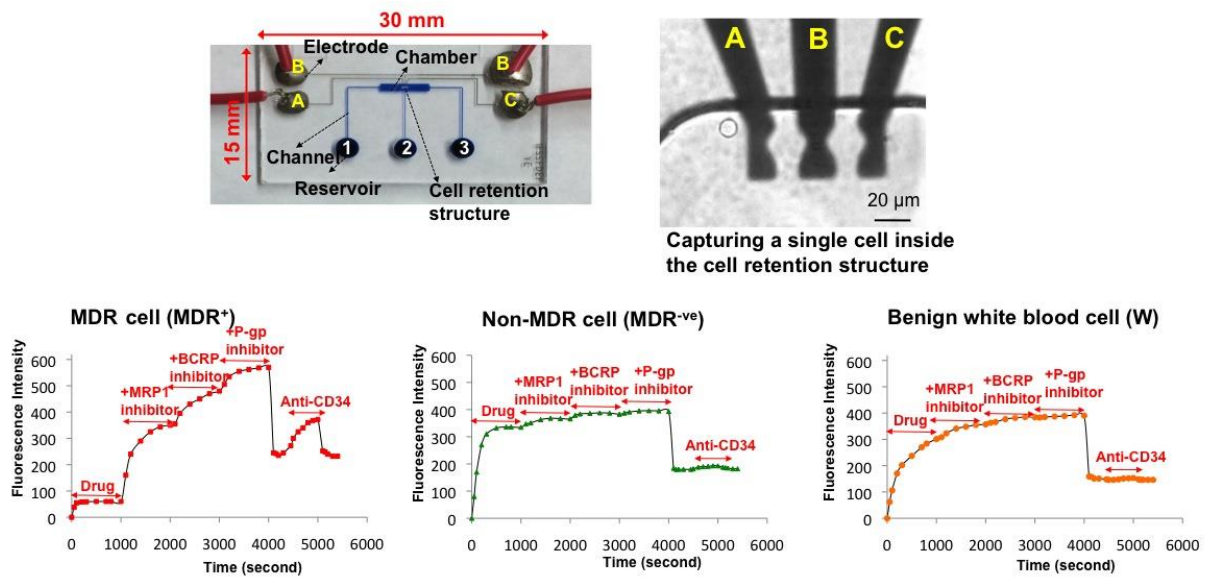

A new dielectrophoresis (DEP) microfluidic chip was fabricated to trap a single cancer cell, followed by subsequent drug accumulation measurement to identify heterogeneity in multidrug resistance (MDR) activity in acute myeloid leukemic (AML) blasts. This novel measurement can be used for future studies to characterize the mechanistic basis for heterogeneity in MDR activity at the individual cancer cells. 
Table S1: AML patient (p-AML) samples

\begin{tabular}{|c|c|c|c|c|c|}
\hline $\begin{array}{l}\text { p-AML } \\
\text { sample }\end{array}$ & Age & Gender & Cytogenetics & Drug regimen $^{*}$ & $\begin{array}{l}\text { Clinical } \\
\text { outcome }\end{array}$ \\
\hline 1 & 72 & M & normal & $7+3$ & Refractory \\
\hline 2 & 70 & F & normal & $7+3$ & $\mathrm{CR}$ \\
\hline 3 & 51 & $\mathrm{M}$ & del 9q & HiDAC + daunorubicin & Refractory \\
\hline 4 & 73 & $\mathrm{~F}$ & del 9q & $7+3$ & CR \\
\hline 5 & 69 & $\mathrm{~F}$ & normal & $7+3$ & CR \\
\hline 6 & 65 & $\mathrm{~F}$ & normal & $7+3$ & CR \\
\hline 7 & 62 & M & trisomy 8 & $7+3$ & CR \\
\hline 8 & 70 & $\mathrm{M}$ & normal & $7+3$ & Refractory \\
\hline 9 & 36 & M & abnormal 3q & Mitoxantrone and cytarabine & Refractory \\
\hline 10 & 54 & $\mathrm{M}$ & complex & HiDAC + daunorubicin & Refractory \\
\hline 11 & 51 & $\mathrm{M}$ & normal & $7+3$ & CR \\
\hline 12 & 69 & $\mathrm{M}$ & normal & $7+3$ & Refractory \\
\hline 13 & 27 & $\mathrm{M}$ & $11 \mathrm{q} 23$ & HiDAC + daunorubicin & CR \\
\hline 14 & 36 & $\mathrm{M}$ & del 5q & HiDAC + daunorubicin & Refractory \\
\hline 15 & 69 & $\mathrm{M}$ & abnormal & $7+3$ & Refractory \\
\hline 16 & 67 & $\mathrm{~F}$ & abnormal & $7+3$ & Refractory \\
\hline 17 & 40 & $\mathrm{M}$ & normal & $7+3+$ mylotarg & CR \\
\hline 18 & 74 & $\mathrm{M}$ & normal & $7+3$ & CR \\
\hline 19 & 44 & $\mathrm{M}$ & normal & $7+3$ & $\mathrm{CR}$ \\
\hline 20 & 72 & M & normal & $7+3$ & Refractory \\
\hline
\end{tabular}

${ }^{*} 7+3$ is a combination of cytarabine and daunorubicin. HiDAC represents high-dose cytarabine. Daunorubicin, cytarabine and mitoxantrone are substrates for MDR transporters; CR means complete remission. 
Table S2: Paired AML patient samples (peripheral blood) pre-therapy and at relapse

\begin{tabular}{|c|c|c|c|}
\hline p-AML\# & \multirow{2}{*}{ Age } & Pre-therapy or relapse & Blast $\%$ \\
\hline p-AML 21 & \multirow{2}{*}{77} & Pre-therapy & BM Blast 94\% \\
& & & PB Blast 92\% \\
\cline { 3 - 4 } & & Relapse & PB Blast 97\% \\
\hline \multirow{2}{*}{ p-AML 22 } & \multirow{2}{*}{45} & After 5 months & BM Blast 71\% \\
& & Pre-therapy & PB Blast 63\% \\
\cline { 3 - 4 } & & Relapse & PB Blast 67\% \\
\cline { 3 - 4 } & & After 6 months & \\
\hline
\end{tabular}

Abbreviations: p-AML: AML patient sample; BM: Bone Marrow; PB: Peripheral Blood 
Table S3: Categorization of examined cells in AML patient samples

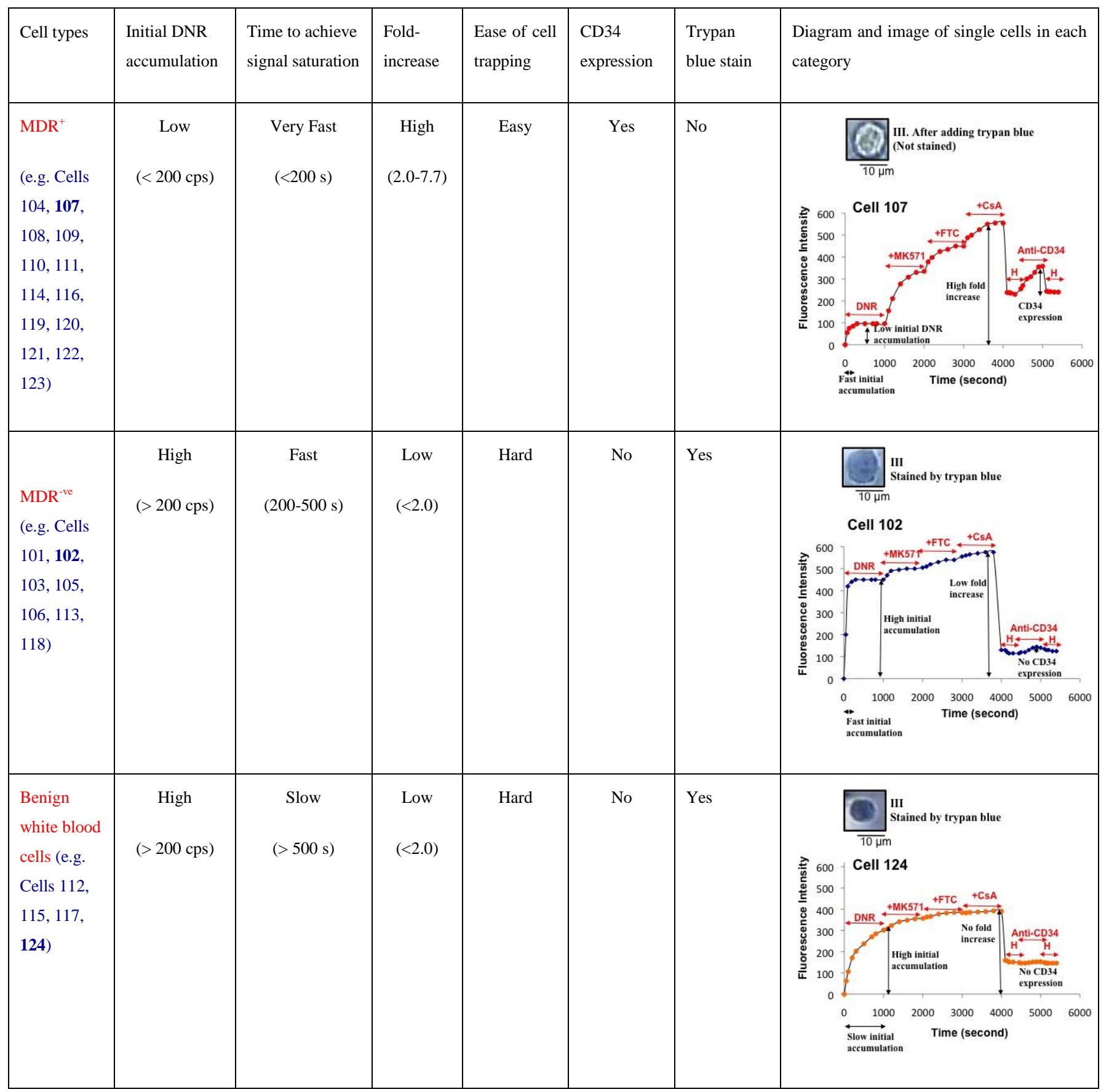

$\mathrm{MDR}^{+}$is MDR (multidrug resistant) cells; $\mathrm{MDR}^{-\mathrm{ve}}$ is non-MDR cells; cps is counts per second; $\mathrm{s}$ is second; DNR is daunorubicin; MK571, FTC and CsA are the MDR inhibitors; H is HBSS; anti-CD34 is CD34 antibody. 


\section{Optimizing DNR and MDR inhibitor concentrations}

Different concentrations $(3.5,7,14,35,70,350 \mu \mathrm{M})$ of DNR were used to determine the reasonable initial signal for drug accumulation in the cell. The initial accumulation signal obtained from $35 \mu \mathrm{M}$ DNR provided the optimal signal $(110 \pm 47$ counts per second or cps).

Since the activities of more than one type of MDR transporters have been reported in the cancer cells of AML patients, the drug accumulation experiments were evaluated on AML single-cells using different categories of MDR inhibitors, specifically MK571 (a MRP1 inhibitor), FTC (a BCRP inhibitor) and CsA (a P-gp inhibitor). As depicted in Figure S1a, after adding different concentrations of FTC (5, 10, 20,40 and $80 \mu \mathrm{M})$, the cell fluorescent signal increased to $125 \pm 52,156 \pm 56,252 \pm 57,261 \pm 57,274 \pm 61 \mathrm{cps}$, respectively, from the initial value of $92 \pm 46 \mathrm{cps}$ (for DNR only). The fluorescence signal plateaued after treating the single-cell with DNR in the presence of $20 \mu \mathrm{M}$ of FTC, which was adopted as optimal concentration for subsequent experiments.

Similar experiments were performed for MK571 and CsA. As shown in Figure S1b, the cell fluorescent signal increased to $153 \pm 51,262 \pm 55,418 \pm 51,435 \pm 56$, and $440 \pm 58 \mathrm{cps}$, from $128 \pm 49 \mathrm{cps}$, after MK571 treatment $(10,20,40,80$ and $100 \mu \mathrm{M}$, respectively). Figure S1c shows the cell fluorescent signal increased from $110 \pm 51 \mathrm{cps}$, to $160 \pm 51,225 \pm 50,430 \pm 52,454 \pm 55,460 \pm 59 \mathrm{cps}$ after CsA treatment $(1,2.5,5,10$ and $20 \mu \mathrm{M}$, respectively). Therefore, $40 \mu \mathrm{M}$ MK571 and $5 \mu \mathrm{M}$ CsA were adopted as the optimal inhibitor concentrations.

Litman et al. reports that the half-saturation concentration for the effect of a MDR inhibitor on the steadystate accumulation level or its half-maximal inhibitory concentration $\left(\mathrm{IC}_{50}\right)$ can be determined by intrinsic cell properties as follows:

$$
I C_{50}=K_{i} \times F I
$$

where $\mathrm{K}_{\mathrm{i}}$ is the intrinsic affinity of the inhibitor to the $\mathrm{ABC}$ transporter at the inner leaflet of the cell membrane $;{ }^{1}$ FI represents fold-increase of cellular drug accumulation, which is the ratio of MDR inhibitorblocked to unblocked accumulation of drug in the cell. Since $\mathrm{IC}_{50}$ depends on the MDR activity or the number of multidrug resistant pumps on the cell membrane, a higher $\mathrm{IC}_{50}$ value is related to a higher foldincrease in drug accumulation due to inhibitor treatment. Litman et al. reported $0.50 \mu \mathrm{M}$ as the mean $\mathrm{K}_{\mathrm{i}}$ for the affinity of CsA for P-gp to DNR treatment across multiple cell lines. ${ }^{1}$ Using this equation, we obtained $2.1 \mu \mathrm{M}$ as the $\mathrm{IC}_{50}$ value of CsA to inhibit the P-gp on a single leukemic blast cell, when the fold-increase was calculated to be 4.2 (i.e. from 110 to 460 in Figure S1c). This value of $2.1 \mu \mathrm{M}$ is comparable with the IC $_{50}$ value of CsA (0.4-1.6 $\left.\mu \mathrm{M}\right)$ for inhibiting P-gp, as previously reported. ${ }^{1}$ 

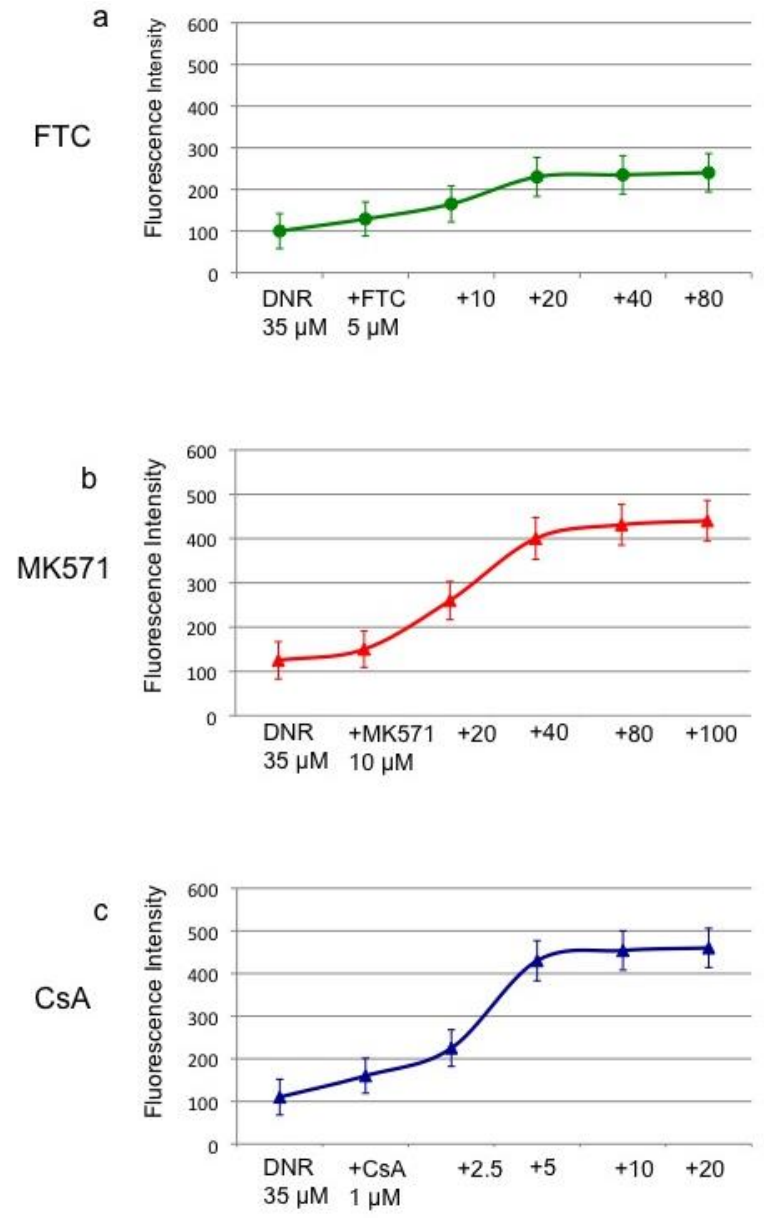

Figure. S1 Effective concentrations of three different MDR inhibitors. DNR accumulation in AML patient single-cells in the presence of different concentrations of (a) FTC (at 5, 10, 20, 40 and $80 \mu \mathrm{M}$ ), (b) MK571 (at 10, 20, 40, 80 and $100 \mu \mathrm{M}$ ) and (c) CsA (at 1, 2.5, 5, 10 and $20 \mu \mathrm{M}$ ). DNR concentration was $35 \mu \mathrm{M}$. Error bars were shown for 100 data points. 
p-AML 9

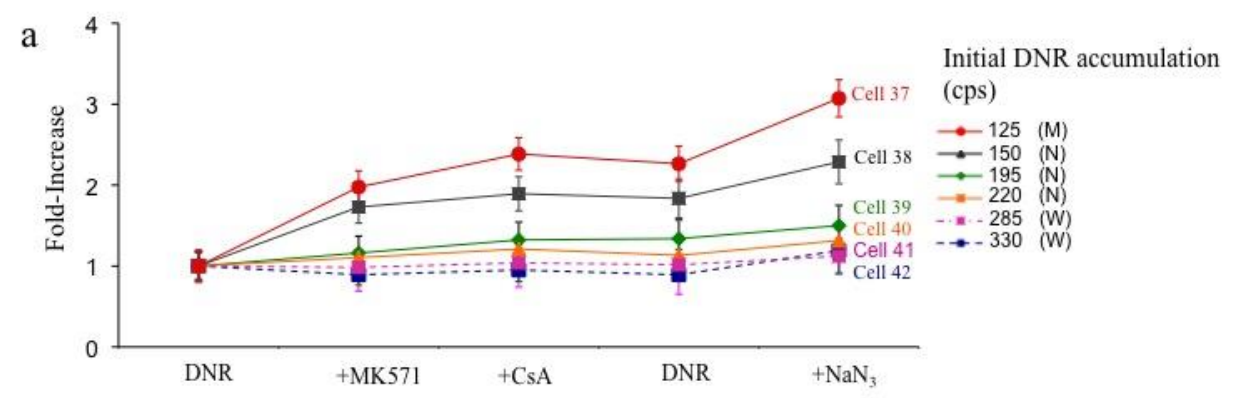

p-AML 16

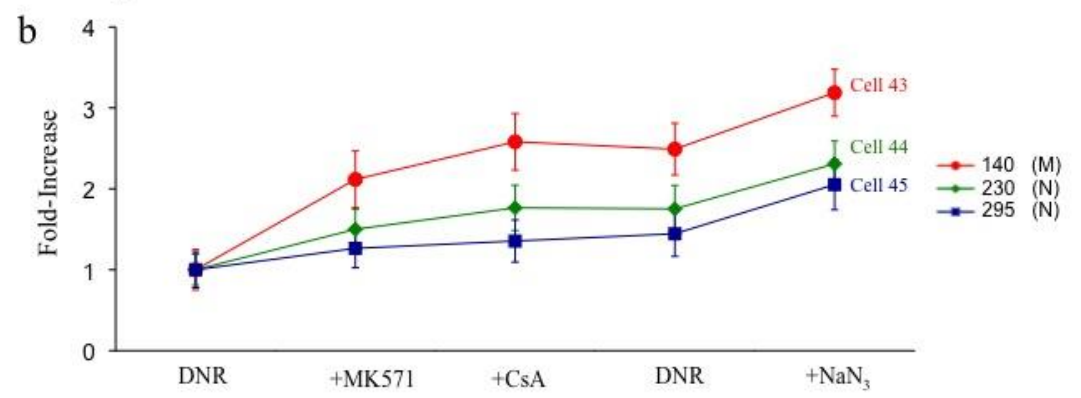

Figure S2. Refractory AML patient samples in which $\mathrm{MDR}^{+}(\mathrm{M})$ cells were expected but few were found, among $\mathrm{MDR}^{-\mathrm{ve}}(\mathrm{N})$ and benign $(\mathrm{W})$ cells. $(\mathrm{a}, \mathrm{b})$ Fold-increases in DNR accumulation in cells obtained from AML patient samples 9 and 16, respectively. The number on the legend represents the initial fluorescent intensity, which is low for MDR ${ }^{+}$cells (Cells 37 and 43). 

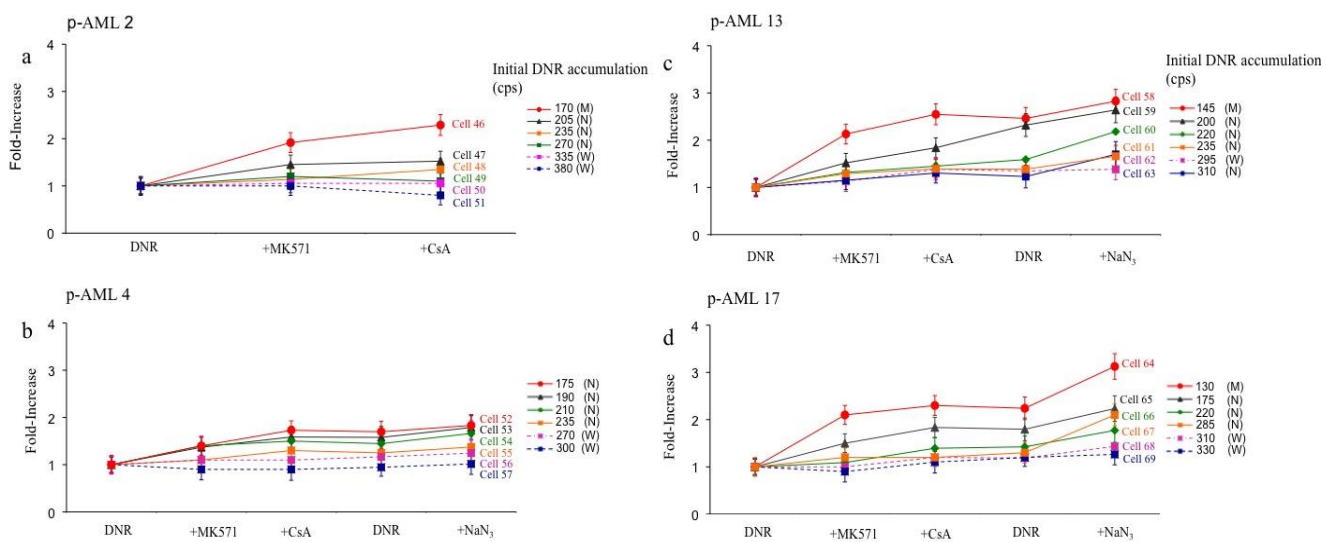

Figure S3. Complete remission (CR) AML patient samples, in which $\mathrm{MDR}^{-\mathrm{ve}}(\mathrm{N})$ cells were expected but $\mathrm{MDR}^{+}(\mathrm{M})$ cells were also found. (a-c) Fold-increases in DNR accumulation in single-cells obtained from AML patients 2, 4, 13 and 17, respectively. Cell 46 from p-AML 2, Cells 58 from p-AML 13, and Cell 64 from p-AML 17 represented the characteristics of $\operatorname{MDR}^{+}(\mathrm{M})$ cells, which had low initial drug accumulation (number beside legend) and subsequent high fold-increase due to inhibitors. 
p-AML 17

a

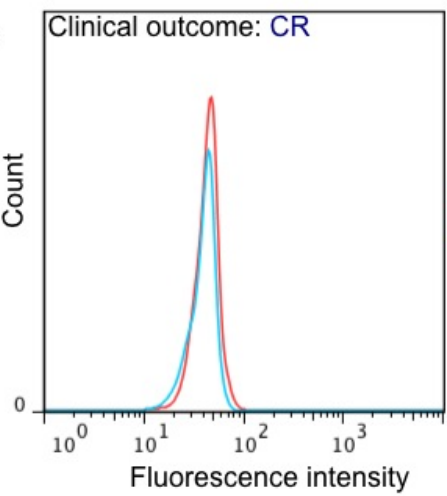

p-AML 9

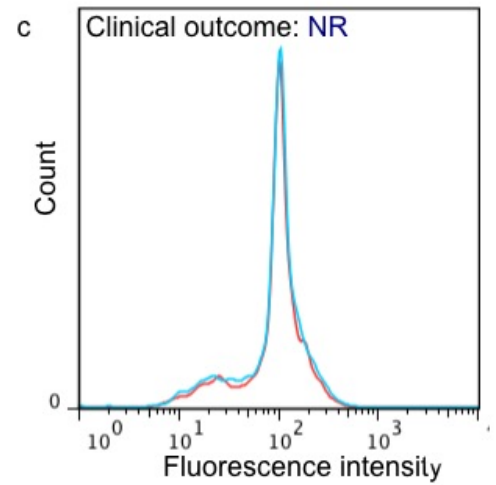

p-AML 19

b

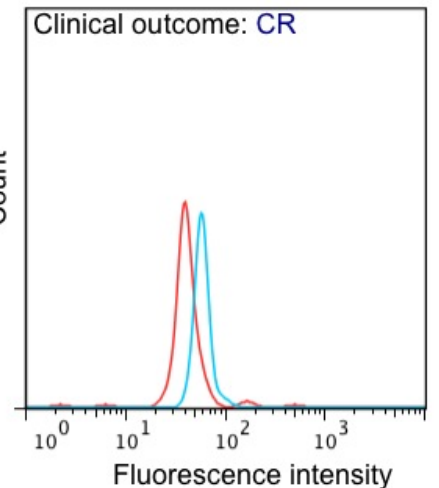

p-AML 20

d

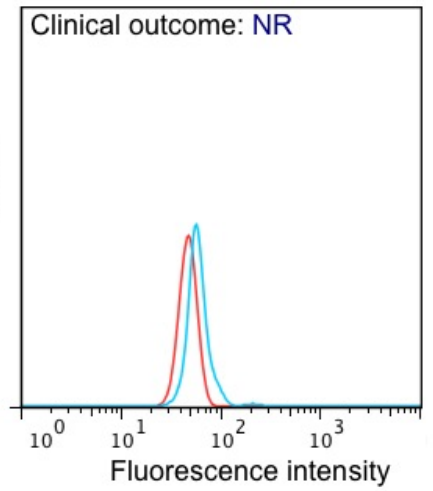

Figure S4. Flow cytometry study of the enhancement of DNR accumulation in p-AML cells by $40 \mu \mathrm{M}$ of MK571. DNR concentration was $35 \mu \mathrm{M}$. Histogram shows an increase of fluorescent intensity (right shift) by adding MRP1 inhibitor to the cells obtained from p-AML 19 (b) and p-AML 20 (d). No shift between the DNR-only peak and DNR+MK571 peak was obtained on cells of p-AML 17 (a) and p-AML 9 (c). 
a

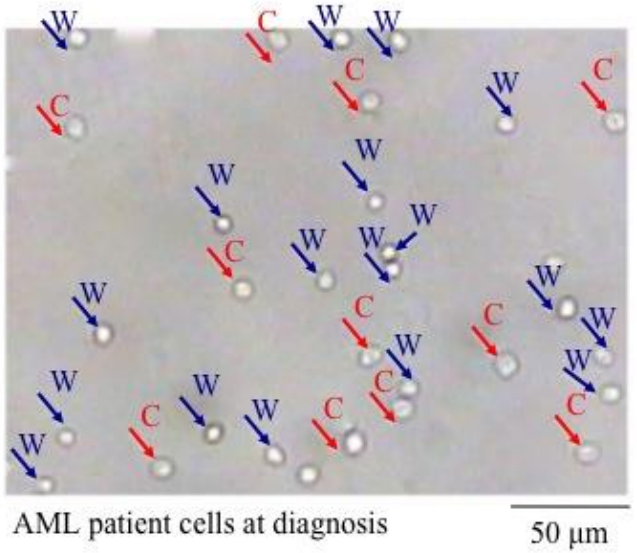

b

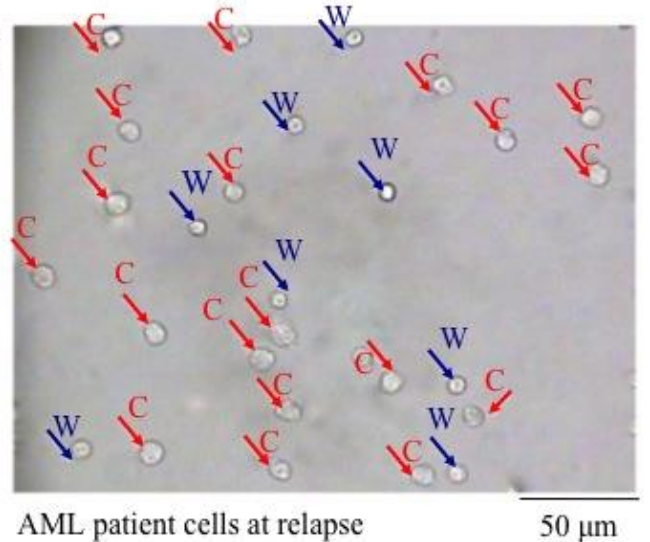

Cancerous cell (C)

Non-Cancerous cell (W)

Figure S5. Morphology of cells obtained from the AML patient sample having a low percentage of blasts at diagnosis (or pre-therapy) (a) and at relapse (b). The bigger cells represent the cancerous $\mathrm{MDR}^{+}$or $\mathrm{MDR}^{-\mathrm{ve}}$ cells ( $\mathrm{C}$ in red); whereas the smaller cells represent the benign cells (W in blue). Even though the blast percentage was low, the $\mathrm{C}$ cells were easily found in the sample. In addition, comparison of the cells in these two samples indicated that it was even easier to select a $\mathrm{C}$ cell in the relapse sample than in the pre-therapy sample since $\mathrm{C}$ cells were more numerous. Scale bar: $50 \mu \mathrm{m}$. 

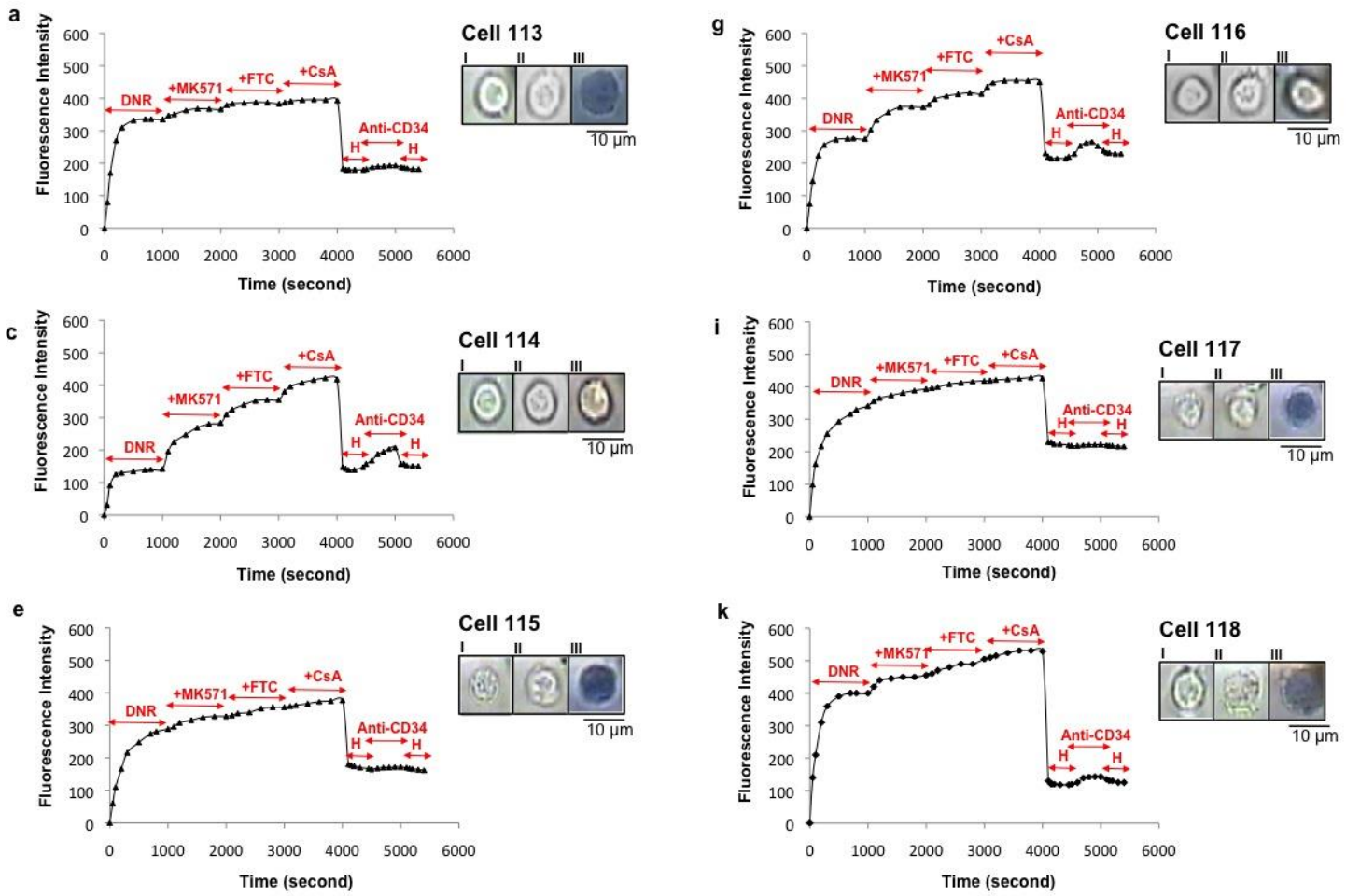

Figure S6. Fluorescent measurement of single-cells obtained from a pre-therapy sample with low percentage of blasts. (a-f) The patient single-cells were treated with drug + MDR inhibitors $(40 \mu \mathrm{M}$ of MK571, 20 $\mu \mathrm{M}$ of FTC and $5 \mu \mathrm{M}$ of CsA). (c,g) Cells 114 and 116 show drug accumulation enhancement after adding inhibitors as well as increased fluorescent intensity after adding anti-CD34. (c,e) In Cells 115 and 117, no DNR enhancement was observed after adding MDR inhibitors. Besides, the plateau was observed at a long time. These two single-cells were characteristics of benign white blood cells that were stained with trypan blue. (a,k) No significant drug enhancement observed in Cells 113 and 118 after adding MDR inhibitors. (aI,II,III-fI,II,III) The images of Cells 113, 114, 115, 116, 117 and 118, respectively, were depicted before and after experiment, followed by adding trypan. Only Cells 114 and 116 were not stained. Scale bar: $10 \mu \mathrm{m}$. 

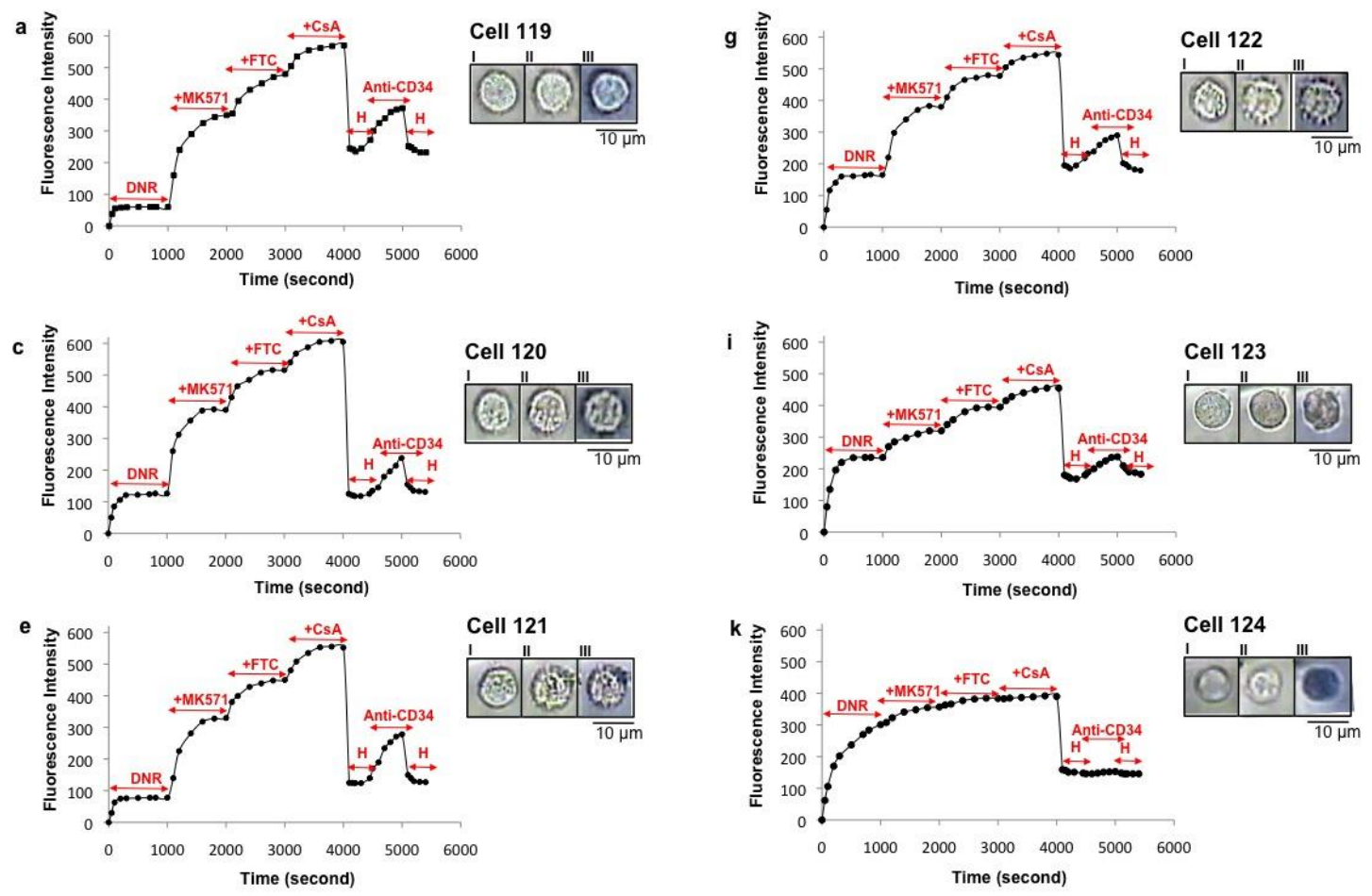

Figure S7. Fluorescent measurement of single-cells obtained from a relapse sample with low percentage of blast. (a-f) The patient single-cells were treated with drug + MDR inhibitors ( $40 \mu \mathrm{M}$ of MK571, $20 \mu \mathrm{M}$ of FTC and $5 \mu \mathrm{M}$ of CsA), followed by adding anti-CD34 antibody. Cells 119-123 showed significant drug accumulation enhancement. In Cell 124, no fold-increase was observed after adding MDR inhibitors. (aI,II,III-fI,II,III) The cell images were depicted before and after experiment, followed by adding trypan blue. Except Cell 124, the rest of cells were not stained by trypan blue, and only unstained cells had the fluorescent intensity increased after adding anti-CD34 antibody. Scale bar: $10 \mu \mathrm{m}$.

\section{Reference}

(1) Litman, T.; Skovsgaard, T.; Stein, W. D. J. Pharmacol. Exp. Ther. 2003, 307, 3, 846-853. 